\title{
Dynamic Systems Development Method dalam Membangun Aplikasi Data Kependudukan Pada Kelurahan Rantau Pulut
}

\author{
Lili Rusdiana \\ Program Studi Teknik Informatika, STMIK Palangka Raya \\ Jl. G.Obos No.114 Palangkaraya, telp.: 0536-3225515, e-mail: fasliiana7@gmail.com
}

\section{ARTICLE INFO}

Article history:

Received 23 July 2018

Received in revised form 30 July 2018

Accepted 3 Agustus 2018

Available online 17 Agustus 2018

\section{ABSTRACT}

\begin{abstract}
Dynamic Systems Development Method (DSDM) can be used as one of the methods in developing and building applications based on the needs and communication of users and developers such as in developing Population Data Application In Rantau Pulut Village. Such as data collection through interviews as one form of communication between developers and users. This research aims to build population applications in Rantau Pulut Village as a solution of data processing both in terms of storage and reporting that can help the processing of data needed to become more effective and efficient as well as a solution for the current system running. Through the stages of DSDM conducted and produce applications that can run in accordance with user needs, especially in terms of reporting generated by the application so that users feel user friendly
\end{abstract}

Keywords: Dynamic Systems Development Method, Rantau Pulut sub-village, Population information system.

\section{Pendahuluan}

Penggunaan metode dalam pengembangan maupun pembangunan aplikasi sangatlah beragam, salah satunya yaitu metode Dynamic Systems Development Method (DSDM) yang dapat digunakan untuk mengembangkan maupun membangun aplikasi secara berulang dan bertambah dengan melibatkan pengguna sebagai kunci utama dan adanya kerjasama antara pengguna dan pengembang. Perkembangan teknologi khususnya di bidang aplikasi dan sistem informasi banyak memberikan manfaat, tidak hanya di bidang pendidikan tetapi juga di bidang pemerintahan. Sistem informasi di bidang pemerintahan dapat digunakan untuk data kepegawaian, data keuangan, atau data masyarakat itu sendiri di lingkungan pemerintahan tersebut baik secara luas maupun sempit seperti data kependudukan pada Kelurahan.

Aplikasi data kependudukan di Kelurahan dapat membantu dalam menyimpan data masyarakat pada Kelurahan tersebut agar petugas mudah dalam memantau data penduduk. Salah satu Kelurahan yang dapat mengimplementasikan aplikasi data kependudukan yaitu Kelurahan Rantau Pulut. Pada kantor Kelurahan di Rantau Pulut, sistem pencatatan dan penyimpanan data kependudukan masih sangat manual, yaitu masih dengan menggunakan lembaran kertas dan buku 
besar untuk mencatat keterangan surat masuk dan surat keluar. Sementara untuk surat keterangan seperti surat keterangan kelahiran, kematian, dan pindah datang hanya disimpan tanpa dilakukan pencatatan untuk rekapitulasi data tersebut. Sistem informasi pengolahan data kependudukan yang pernah dibangun untuk Desa Purwoasri [1] merupakan sistem yang menyediakan aplikasi tidak hanya memudahkan petugas dalam mencatat data tetapi juga memudahkan masyarakat dalam hal surat-penyurat yang berhubungan dengan data kependudukan yang diperlukan.

Aplikasi yang dibangun pada penelitian ini meliputi pengolahan data penduduk datang, pengolahan data penduduk pindah datang, pengolahan data kelahiran, pengolahan data kematian, dan pengolahan biodata keluarga sehingga menghasilkan laporan seperti data keluarga dan pencetakan surat keterangan. Dalam membangun aplikasi data kependudukan maka DSDM dapat diterapkan dengan tahapan-tahapan yang dimiliki oleh DSDM sehingga dapat menghasilkan aplikasi yang efektif dan efisien serta user friendly untuk penggunanya karena adanya kerjasama antara pengguna dan pengembang. DSDM telah digunakan untuk mengembangkan perangkat lunak website komunitas dalam suatu institusi, dari setiap langkah pada DSDM mampu mendefinisikan kebutuhan yang diperlukan dalam membangun perangkat lunak tersebut [2].

\section{Landasan Teori}

\subsection{Dynamic Systems Development Method (DSDM)}

DSDM merupakan salah satu metode Agile untuk pengembangan perangkat lunak. DSDM merupakan suatu kerangka kerja yang awalnya didasarkan pada Rapid Application Development (RAD) dan mengutamakan keterlibatan pengguna secara berkesinambungan dengan pendekatan pengembangan secara berulang dan bertambah, tanggap terhadap perubahan, untuk membangun sistem perangkat lunak yang memenuhi kebutuhan bisnis tepat waktu dan juga tepat anggaran.

Terdapat 9 prinsip mendasar dari DSDM, yang menjadikan kekuatan dari DSDM, yaitu [3]:

a. Keterlibatan pengguna adalah kunci utama dalam menjalankan proyek secara efisien dan efektif. Pengguna dan pengembang saling bekerja sama sehingga keputusan dapat diambil secara tepat dan akurat.

b. Tim pengembang proyek diberi wewenang untuk membuat keputusan yang penting untuk kemajuan proyek, tanpa menunggu persetujuan dari tingkat di atasnya.

c. Memusatkan pada seringnya sistem dihasilkan, dengan anggapan menghasilkan sesuatu 'cukup baik' lebih awal adalah lebih baik daripada menghasilkan keseluruhan 'sempurna' pada akhirnya. Dengan seringnya penyampaian sitem pada tahap-tahap awal proyek, sistem tersebut dapat diujicoba dan ditinjau dan hasilnya merupakan pertimbangan untuk maju ke putaran atau tahap berikutnya.

d. Kesesuaian dari tujuan bisnis merupakan kriteria utama dalam penerimaan hasil. Menghasilkan suatu sistem yang memenuhi semua kemungkinan dari kebutuhan bisnis adalah kurang penting dibanding memusatkan pada fungsi-fungsi yang kritis.

e. Pentingnya pengembangan secara berulang dan bertambah, dilandasi masukan dari pengguna untuk mencapai solusi bisnis yang efektif.

f. Seluruh perubahan yang terjadi dalam pengembangan dapat dikembalikan (reversible).

g. Setiap persyaratan dan kebutuhan harus sudah ditentukan sebelum proyek dimulai.

h. Pengujian dilakukan pada keseluruhan siklus hidup proyek. Dalam hal ini ujicoba bukan kegiatan terpisah dalam pengembangan. Tinjauan dari pengembang dan pengguna merupakan hal penting untuk memastikan proyek berjalan baik dari sisi bisnis maupun teknis.

i. Kerjasama yang efektif dan efisien dari setiap pihak yang berkepentingan adalah penting. DSDM terdiri dari 3 tahapan utama, dan 5 sub tahap.

Tahapan utama adalah sebagai berikut:

a. Sebelum proyek, kandidat proyek diidentifikasi, pembiayaan proyek terpenuhi, dan jaminan proyek dipastikan. Penanganan hal-hal tersebut pada tahap ini menghindari masalah pada tahap-tahap berikutnya.

Dynamic Systems Development Method dalam Membangun Aplikasi Data Kependudukan Pada Kelurahan Rantau Pulut. (Lili Rusdiana) 
b. Siklus hidup proyek, merupakan inti dari DSDM, yang terdiri dari 5 sub tahap yaitu :

1) Studi kelayakan.

2) Studi bisnis.

3) Perulangan model fungsional.

4) Perulangan perancangan dan pembuatan.

5) Penerapan.

c. Setelah proyek, yaitu memastikan sistem berjalan secara efektif dan efisien. Hal ini diwujudkan dengan perawatan, peningkatan dan perbaikan sesuai prinsip-prinsip DSDM. Perawatan dapat dilihat sebagai usaha meneruskan pengembangan berdasarkan sifat alami DSDM, yaitu perulangan dan pertambahan.

\subsection{Data Kependudukan}

Data Kependudukan adalah data perseorangan atau data agregat yang terstruktur sebagai hasil kegiatan pendaftaran penduduk dan pencatatan sipil [4]. Data perseorangan menurut UU No. 24 Tahun 2013, pasal 58 ayat 2, meliputi nomor Kartu Keluarga; Nomor Induk Kependudukan; nama lengkap; jenis kelamin; tempat lahir; tanggal/bulan/tahun lahir; golongan darah; agama/kepercayaan; status perkawinan; status hubungan dalam keluarga; cacat fisik dan/atau mental; pendidikan terakhir; jenis pekerjaan; NIK ibu kandung; nama ibu kandung; NIK ayah; nama ayah; alamat sebelumnya; alamat sekarang; kepemilikan akta kelahiran/surat kenal lahir; nomor akta kelahiran/nomor surat kenal lahir; kepemilikan akta perkawinan/buku nikah; nomor akta perkawinan/buku nikah; tanggal perkawinan; kepemilikan akta perceraian; nomor akta perceraian/surat cerai; tanggal perceraian; sidik jari; iris mata; tanda tangan; dan elemen data lainnya yang merupakan aib seseorang.

Dalam keputusan Mentri Dalam Negeri No.54 tentang kependudukan pedoman penyelenggaraan pendaftaran penduduk yang dijelaskan diantaranya :

a. Penduduk. Penduduk adalah Warga Negara indonesia (WNI) dan Warga Negara Asing (WNA) pemegang ijin tinggal tetap di wilayah Negara kesatuan republik Indonesia atau semua orang yang berdomisili di desatersebut selama enam bulan lebih atau mereka yang berdomisili kurang dari enam bulan tetapi bertujuan menetap.

b. Keluarga. Keluarga merupakan unit terkecil dalam masyarakat yang mempunyai hubungan darah dan orang lain yang tinggal dalam satu rumahatau bangunan yang terdaftar dalam kartu keluarga.

c. Kepala Keluarga. Laki-laki atau perempuan yang berstatus kawin, janda atau duda yang mengepalai satu keluarga yang anggotanya terdiri dari isteri atausuami dan anak-anak.

d. Anggota Keluarga. Mereka yang tercantum dalam satu Kartu keluarga dua orang atau lebih dan salah satu ada yang menjadi kepala keluarga.

e. Dinamika Kependudukan

1) Kelahiran, merupakan proses penambahan jumlah penduduk yang diakibatkan oleh hal dari suatu perkawinan.

2) Kematian, merupakan proses pengurangan penduduk yang diakibatkan oleh meninggalnya penduduk.

f. Migrasi (Pindah) terbagi menjadi dua pengertian

1) Warga masuk, merupakan proses penambahan penduduk yang berasal dari satu tempat ke tempat lain.

2) Warga keluar, merupakan proses pengurangan penduduk yang keluar atau pindah dari satu tempat ke tempat lain.

TRANSFORMATIKA Vol. 16, No. 1, Juli 2018: $84-90$ 
g. Identitas Kependudukan

1) Nomor Induk kependudukan (NIK), merupakan nomor identitas yang diberikan kepada setiap penduduk diwilayah Negara Kesatuan Republik Indonesia pada saat yang bersangkutan didaftar sebagai penduduk. Dan setiap penduduk hanya diberikan satu nomor induk kependudukan yang berlaku seumur hidup.

2) Kartu Tanda Penduduk (KTP), merupakan sebagai bukti bagi setiap penduduk yang sudah berumur minimal 17 tahun atau telah menikah yang terdaftar diwilayah pemerintahan.

h. Laporan Buku Induk Kependudukan.

Laporan Buku Induk Kependudukan merupakan buku catatan yang memuat data awal setiap penduduk dalam satu wilayah desa atau kelurahan yang wajib dilaporkan kepada kecamatan setiap akhir semester.

\subsection{Lembar Kerja Tampilan (LKT)}

Rancangan antarmuka menggunakan Lembar Kerja Tampilan (LKT) sebagai salah satu alat untuk mendesain tampilan adalah dengan menggunakan lembar kerjauntuk desain layar. Desain antarmuka dapat menggunakannya dalam bentuk lembaran kertas untuk memudahkan dokumentasi. Ini akan sangat berguna bagi para programmer untuk membangun program [5]. Lembar kerja desain layar terdiri dari 4 bagian seperti pada gambar 2 dan gambar 3 dengan komponen sebagai berikut:

a. Nomor lembar kerja

Nomor ini berdasarkan jumlah tampilan yang dibuat.

b. Tampilan

Desain tampilan yang akan muncul di layar.

c. Navigator

Penjelasan tampilan yang dirancang.

d. Keterangan

Deskripsi bagian-bagian tampilan.

Rancangan antarmuka menggunakan LKT yang menggambarkan rancangan dari aplikasi yang dibangun baik bersifat penyimpanan data maupun hanya bersifat perhitungan. Aplikasi yang pernah dibangun menggunakan LKT Seperti untuk menampilkan perhitungan dengan menggunakan metode algoritma K-Nearest Neighbour (KNN) dalam menentukan predikat kelulusan Mahasiswa (telah lulus dan belum lulus) berdasarkan beban studi, jumlah IPK, dan kelulusan skripsi pada mahasiswa STMIK Palangkaraya [6].

\section{Hasil dan Pembahasan}

\subsection{Teknik Analisis Data}

Teknik analisis data yang digunakan dalam penulisan ini yaitu mengadopsi beberapa teknik yang terdapat dalam model Agile yaitu Dynamic Systems Development Method (DSDM), terdiri dari 3 tahapan utama, dan 5 sub tahap seperti pada gambar 1. 


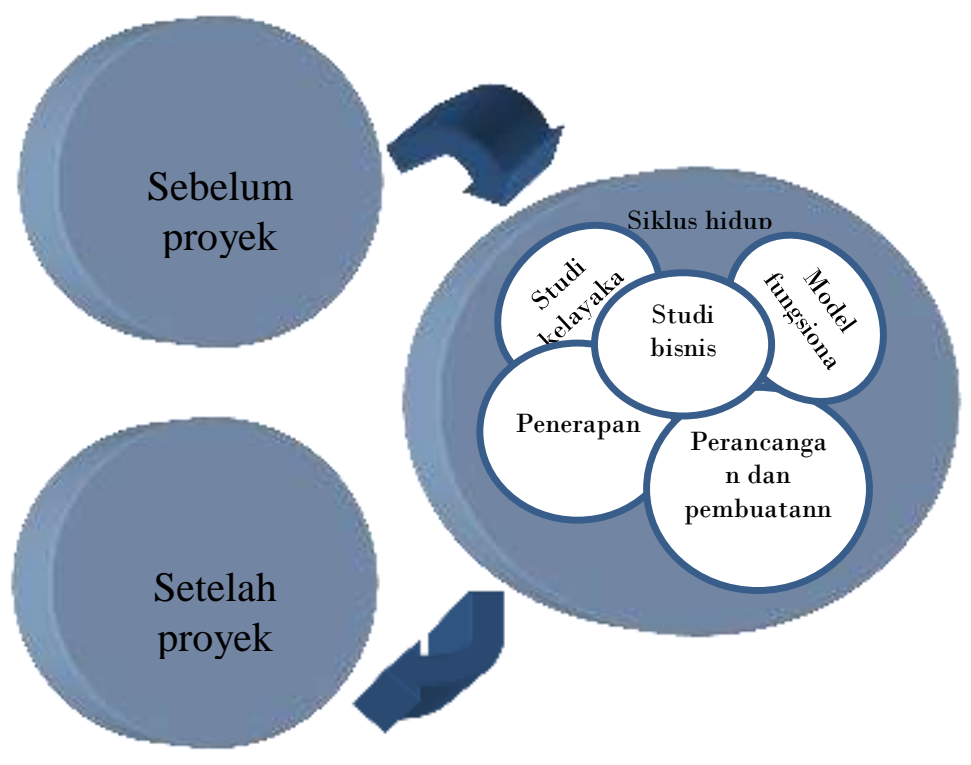

Gambar 1. Tahapan DSDM

Langkah-langkah DSDM yang digunakan dalam penulisan ini seperti pada Gambar 1, yaitu sebagai berikut:

a. Sebelum proyek

Sebelum proyek dilakukan, terlebih dahulu mengajukan proposal yang berisi :

1) Pengajuan tempat untuk penelitian dan nara sumber yang diperlukan

2) Biaya yang diperlukan

3) Waktu yang dibutuhkan

4) Rencana pembangunan aplikasi

Proposal diajukan untuk mendapatkan persetujuan terkait 4 hal di atas dengan bukti adanya surat tugas dan surat izin untuk melakukan proyek yang dalam hal ini yaitu penelitian seperti pada lampiran 1 dan lampiran 2. Hal tersebut diatas dilakukan agar dapat menjadi penanganan pada tahap ini untuk menghindari masalah pada tahap-tahap berikutnya.

b. Siklus hidup proyek, merupakan inti dari DSDM, yang terdiri dari 5 sub tahap yaitu :

1) Studi kelayakan.

Tahap ini mengenai persiapan di lingkungan internal pengembang, salah satunya mengadakan pertemuan dari seluruh anggota yang akan terlibat, yakni antara peneliti dan staff pada kantor kelurahan maupun Lurah itu sendiri. Hasil yang dicapai dari pertemuan ini yaitu:

a) Peninjauan kelayakan pengembangan aplikasi yang akan digunakan, dalam hal ini yaitu penggunaan DSDM.

b) Adanya garis besar rencana seperti pada batasan masalah yang diajukan.

2) Studi bisnis.

Tahapan ini memerlukan keterlibatan nara sumber di tempat penelitian yakni lurah beserta staf yang akan menjadi admin pada aplikasi yang dibangun dan juga peneliti agar dapat mensinkronkan pembangunan aplikasi yang diajukan. Mengetahui yang diperlukan oleh nara sumber seperti pembangunan aplikasi yang terdiri dari data perseorangan, data keluarga, data tempat tinggal, data kelahiran, data kematian, data pindah, data pindah datang baik yang bersifat penyimpanan maupun pelaporan.

TRANSFORMATIKA Vol. 16, No. 1, Juli 2018: $84-90$ 
3) Perulangan model fungsional.

Tahapan ini membahas tentang pembangunan aplikasi yang sebelumnya telah dilakukan perancangan menggunakan DFD dan LKT.

4) Perulangan perancangan dan pembuatan.

Tahapan ini sering terjadi seiring dengan berjalannya pembangunan aplikasi, perancangan dan pembangunan aplikasi menggunakan pengkodean yang terdapat pada bahasa pemrograman Visual Basic dan Database menggunakan Microsoft Office Access sebagai media penyimpanan dan Microsoft Office Word sebagai tampilan laporan (sesuai saran dan permintaan kebutuhan dari tempat penelitian). Perulangan sering terjadi dalam pengujian model dan penggunaan aplikasi sebagai sistem baru terhadap sistem yang berjalan saat ini untuk mengetahui hasil dari model yang digunakan sehingga didapat suatu kesimpulan mengenai layanan atau fitur dan fungsionalitas yang terdapat pada aplikasi yang dibangun.

5) Penerapan.

Setelah dilakukan pengujian maka adanya implementasi untuk menerapkan sistem yang dibangun yakni menerapkan pada kantor kelurahan Rantau Pulut dengan dukungan admin yang sesuai dan mengerti dalam menjalankan aplikasi.

c. Setelah proyek

Setelah tahapan dalam DSDM pada siklus hidup proyek dilakukan berulang-ulang hingga keseluruhan aplikasi dapat terbangun dan layak digunakan untuk memastikan aplikasi dapat berjalan dan digunakan secara efektif dan efisien. Perawatan, peningkatan dan perbaikan dapat dilakukan seiring dengan penggunaan aplikasi agar dapat dilakukan pengembangan untuk lebih baik lagi berdasarkan tahapan pada DSDM, yaitu perulangan dan pertambahan.

\subsection{Rancangan Antarmuka}

Rancangan antarmuka (interface) berdasarkan pada data input dan output yang diperlukan dalam pembangunan aplikasi data kependudukan. Rancangan antarmuka menggunakan LKT seperti pada Gambar 2 dengan beberapa kolom yang digunakan dalam tampilan menu login dan gambar 3 untuk rancangan tampilan halaman menu utama.

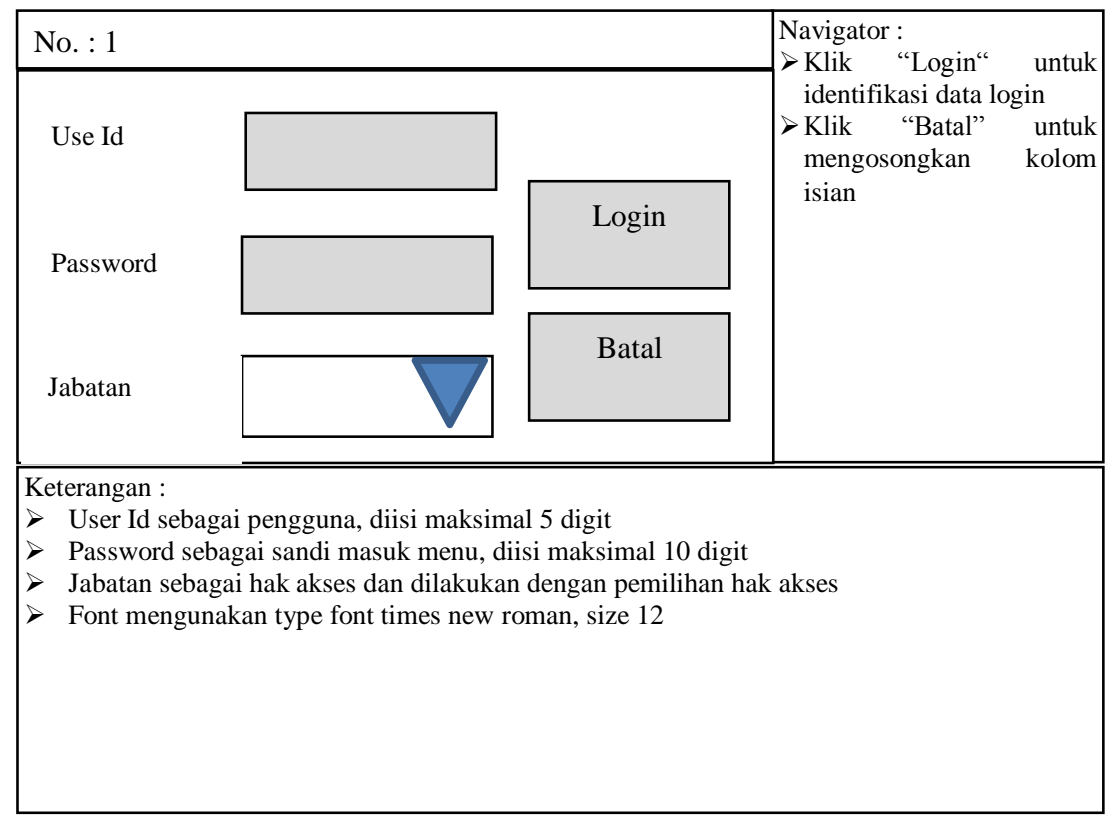

Gambar 2. Desain tampilan halaman menu login 


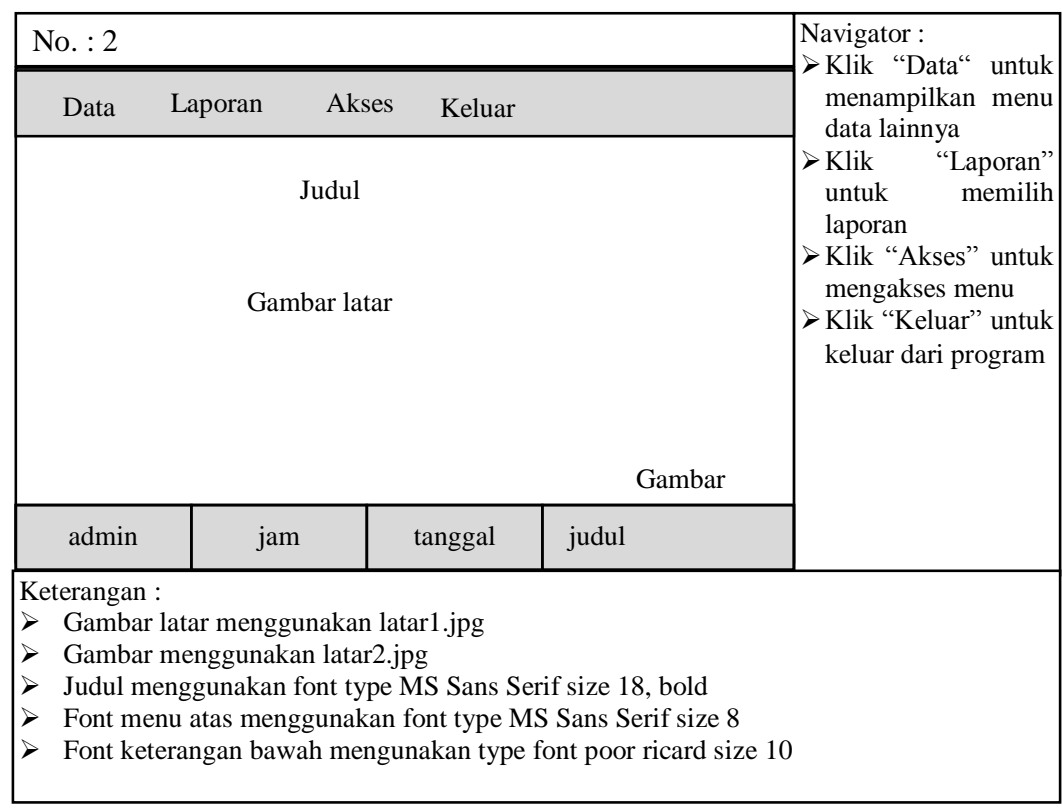

Gambar 3. Desain tampilan halaman menu utama

\section{Kesimpulan}

Pada penelitian ini dapat diambil kesimpulan sebagai berikut:

a. Metode DSDM digunakan selama pembangunan aplikasi dan sangat membantu seperti dengan adanya komunikasi antara tempat penelitian dan pengembang dalam mengembangkan aplikasi, salah satunya yaitu adanya permintaan untuk menampilkan laporan menggunakan software Microsoft Office Word yang dirasa oleh user bahwa tampilan lebih user friendly.

b. Dari hasil aplikasi yang dibangun, didapat bahwa data dapat tersimpan lebih akurat dari pada yang terjadi selama ini ditempat penelitian. Selain itu, penyimpanan data tidak perlu menggunakan penyimpanan dalam bentuk tumpukan kertas. Tampilan laporan yang familiar membuat user lebih merasa mudah karena tampilannya yang lebih user friendly.

c. Pengembangan dapat dilakukan dengan menggunakan metode agile lainnya seperti extreme programming dan pengembangan dari segi tekhnologi yakni dapat diakses secara mobile.

\section{Daftar Pustaka}

[1] Fujiyati Y. Sistem Informasi Pengolahan Data Kependudukan Di Desa Purwoasri. Speed Journal - Sentra Penelitian Engineering dan Edukasi. 2014; 11(4) : 51-58.

[2] Pardede J, Lisa K, Fachri R.P. Implemestasi Dynamic System Development Method Pada Pembangunan Web Komunitas Institut Teknologi Nasional. Jurnal Informatika. 2011; 2(3) : 38-47.

[3] Pressman R.S. Software Engineering: A Practitioner's Approach, Seventh Edition. United State : McGraw-Hill. 2009. 84-85

[4] Undang-Undang Republik Indonesia Nomor 24 Tahun 2013 Administrasi Kependudukan

[5] Santoso I. Interaksi Manusia dan Komputer. Yogyakarta : Andi. 2010.

[6] Rusdiana L, Marfuah. The Application of Determining Students' Graduation Status of STMIK Palangkaraya Using K-Nearest Neighbors Method. Earth and Environmental Science. 2017; 97 012040: 1-8.

TRANSFORMATIKA Vol. 16, No. 1, Juli 2018: $84-90$ 